\title{
КОНЦЕПТУАЛЬНЫЕ И ПРАВОВЫЕ АСПЕКТЫ ПРОВЕДЕНИЯ ПУБЛИЧНЫХ СЛУШАНИЙ В РОССИЙСКОЙ ФЕДЕРАЦИИ
}

Аннотация. Статья посвящена исследованию идеалов и правовых аспектов технологий, используемых при проведении публичных слушаний, являющих собой современную форму Российской муниципальной делиберальной демократии.В работе исследовано состояние идейных, исторических и правовых основ публичных слушаний, как формы институционализированного диалога, рационального дискурса, обсуждения, убеждения, аргументации, компромиссов муниципальной власти и местного сообщества. С учетом анализа наработанной практики проведения публичных слушаний в различных российских муниципалитетах в статье рассматриваются соответствующие базовые идеи и проблемы их практической реализации, рассматриваются правовые аспекты основных технологических проблем, возникающих при проведении публичных слушаний, предлагаются направления совершенствования соответствующего правового института и дается прогноз в отношении приоритетных направлений его развития.Публикация подготовлена в рамках поддержанного РГНФ научного проекта №16-03-50015. При исследовании вопросов функционирования современного института публичных слушаний автор исходит из предположения о том, что функционирование форм диалоговой демократии должно строиться на базовых принципах, выработанных тысячелетней практикой функционирования общественных институтов российского государства. На основе уяснения логики и закономерностей их развития, а также исторического анализа основных сущностных характеристик таких исторических форм российской диалоговой демократии, как Вече, Копа, Круг (сход), Земский собор, действовавших на общих принципах подготовки, организации и проведения, предполагается проанализировать содержание наиболее близкого современного их аналога и сформулировать предложения по совершенствованию соответствующей нормативной базы публичных слушаний. Формулируя направления совершенствования современного российского правового института публичных слушаний следует выделить следующие практические предложения, направленные на совершенствование его содержания.1. Необходимо расширять вариативность форм проведения публичных слушаний.2. Есть смысл в положениях о публичных слушаниях четко закреплять основания для отказа инициативной группе граждан в проведении публичных слушаний.3. Назрела необходимость в нормативной регламентации оснований для проведения повторных публичных слушаний по одному и тому же вопросу.4. Представляется обоснованным нормативно ограничить объем представительства муниципальных и государственных служащих в составе комиссии по проведению публичных слушаний. 5. Есть смысл в положениях о публичных слушаниях развести понятия право на участие в публичных слушаниях и право на выступление в публичных слушаниях, закрепив преимущественное право на осуществление последнего за жителями муниципального образования, представляющими крупные территориальные, социальные или профессиональные группы местного населения и пользующихся их поддержкой и уважением.6. Исходя из практики проведения публичных слушаний разумно будет нормативно закрепить на федеральном уровне правила определения времени и места проведения публичных слушаний. 7. Имеется необходимость законодательного запрета на проведение публичных слушаний одновременно по нескольким вопросам или объектам, расположенным в разных частях муниципального образования одним и тем же составом участников публичных слушаний. 8. Есть смыл нормативно закрепить на федеральном уровне запрет на проведение голосования по вопросам, вынесенным на публичные слушания, в целях определения результатов публичных слушаний в форме рекомендаций, отражающих мнение большинства участников публичных слушаний.9. Назрела необходимость нормативной формализации и конкретизации оснований учета или неучета результатов публичных слушаний органами и должностными лицами местного самоуправления.

Ключевые слова: делиберальная демократия, публичные слушания, идеалы публичных слушаний, местное самоуправление, муниципальный диалог, технологии публичных слушаний, формы местного самоуправления, проведение публичных слушаний, практика публичных слушаний, развитие публичных слушаний. 
Abstract. The article considers the ideals and the legal aspects of the technologies, used in public hearings, which are the contemporary form of Russian municipal deliberative democracy. The author studies the state of conceptual, historical and legal grounds of public hearings as a form of an institutionalized dialogue, rational discourse, discussion, persuasion, argumentation and compromises between municipal authorities and local communities. Taking into account the practice of public hearings in different Russia's municipalities, the author considers the corresponding basic ideas and problems of their organization; studies the legal aspects of technical problems, which can appear during public hearings; offers the ways to improve this public institution and forecasts the priority directions of its development.

The study is carried out within the scientific project No 16-03-50015 of Russian Fund for the Humanities.

The author derives from the presumption that the functioning of deliberative democracy should be based on the fundamental principles of the thousand-year practice of Russian social institutions. The author analyzes the logics and patterns of their development and the historical forms of Russian deliberative democracy (Veche, Kopa, Krug (meeting), zemsky sobor), which had been based on common principles of organization and realization. Based on the results of this analysis, the author attempts at analyzing their closest modern analog and formulating the proposals about the improvement of the current statutory framework of public hearings. The author outlines the following practical recommendations:

It is necessary to extend the variations of forms of public hearings

It might be reasonable to legislate the grounds for the refusal of public hearings organization

It is necessary to regulate the grounds for second public hearings on the same question

It might be reasonable to limit the representation of municipal and public officers in public hearings commissions

It is necessary to distinguish between the concepts of the right to participate in public hearings and the right to speak in public hearings, and to assign the priority right to speak to the citizens of the municipal entity, representing the significant territorial, social or professional groups of local population, widely supported and respected.

Based on the public hearings practice, it might be reasonable to legislate the rules of defining the time and the place of public hearings.

It is necessary to prohibit the organization of public hearings on several issues or objects, located in different parts of the municipal entity, at the same time, by the same participants.

It might be reasonable to legislate the prohibition of voting on the issues, brought up for public hearings, aimed at defining the results of public hearings in the form of recommendations, reflecting the opinion of the majority of the participants of public hearings.

It is necessary to formalize and clarify the reasons for the results of public hearings regarding or ignoring by local authorities or officials.

Key words: organization of public hearings, forms of local government, technologies of public hearings, municipal dialogue, local government, ideals of public hearings, public hearings, deliberative democracy, practice of public hearings, development of public hearings.

Если деятельность научно-обоснованная, а результаты плохие,

то нужно начинать ревизию стандартов. Концептуальный афоризм

$\mathrm{P}$ ассматривая генезис современной системы российского местного самоуправления следует обратить особое на тот факт, что в ее содержании (наряду с формами непосредственной и представительной демократии) в последнее время начинают приобретать все большее значение формы так называемой делиберальной (диалоговой) демократии, представляющей собой совокупность форм институционализированного диалога, рационального дискурса, обсуждения, убеждения, аргументации, компромиссов муниципальной власти и местного сообщества $[1$, с. 40]. Делиберативная (диалоговая) демократия (демократия обсуждения, консультативная демократия), как общественный феномен, сочетает в себе элементы представительной демократии (representatative democracy), прямой демократии (direct democracy) и демократии участия (participatory democracy) [2].

В общественной жизни современных муниципалитетов используется немало форм правовой институализации и налаживания диалога органов местного самоуправления и местного сообщества, таких как сходы, собрания и конференции граждан; работа муниципальных общественных палат и общественных советов; интерактивные телепередачи с участием представителей власти. Однако, в нашем понимании, наиболее важное значение в современной системе российской диалоговой демократии играет такая ее форма, как публичные слушания, представляющие собой форму участия жителей муниципального образования в осуществлении местного самоуправления путем обсуждения проектов муниципальных правовых актов по вопросам местного значения, проводимого органами местного самоуправления в соответствии с установленной процедурой в целях выявления спектра мнений населения муниципального образования. 


\section{Административное и муниципальное право 10 (106) 2016}

Публичные слушания (как отдельный правовой институт муниципального права) были закреплены в виде самостоятельной формы участия населения в осуществлении местного самоуправления и введены в российскую муниципальную практику относительно недавно (в 2003 году). Однако, это совсем не означает, что данный правовой институт привнесен из западных демократий и является чуждым элементом для российской практики осуществления населением самоуправления.

Используемые при проведении современных публичных слушаний идеи и технологии имеют глубокие историко-культурные и социальные корни, так как они отражают менталитет и традиции социокультурного наследия россиян, предусматривающие совместное («сообща», «всем миром») обсуждение наиболее важных вопросов как государственной, так и общественной жизни [3, с. 36]. Их истоки можно проследить в практике проведения Вечевых собраний в Древнерусском государстве, Земских собраний [4] и Копных собраний [5], а также и Казачьих кругов, регулярно и повсеместно проводившихся вплоть до 18 века на многих территориях, входящих в настоящее время в состав современной Российского государства.

Однако, проведение аналогии между указанными историческими формами российской диалоговой демократии и современной ее формой в виде публичных слушаний является достаточно условным в силу того обстоятельства, что указанные институты, несмотря на концептуальную общность, все же имеют значимые отличия по своим содержательно-правовым характеристикам, требующим серьезного осмысления.

В связи с этим, в рамках данного исследования с учетом мнения В.О. Ключевского о том, что «историческое изучение прошлого любого народа своими конечными выводами подходит вплоть к практическим потребностям текущей минуты, требующей от нас, от каждого русского человека, отчетливого понимания накопленных народом средств и допущенных или вынужденных недостатков» [6, с. 60], с учетом опыта функционирования исторических форм российской диалоговой демократии и современной практики проведения публичных слушаний в России, автором предполагается сформулировать и предложить как теоретические, так и практические предложения по совершенствованию российского института публичных слушаний.

\section{Методика исследования института публичных слушаний}

При исследовании вопросов функционирования современного института публичных слушаний автор исходит из предположения о том, что функци- онирование форм диалоговой демократии должно строиться на базовых принципах, выработанных тысячелетней практикой функционирования общественных институтов российского государства. На основе уяснения логики и закономерностей их развития, а также исторического анализа основных сущностных характеристик таких исторических форм российской диалоговой демократии, как Вече, Копа, Круг (сход), Земский собор, действовавших на общих принципах подготовки, организации и проведения, предполагается проанализировать содержание наиболее близкого современного их аналога и сформулировать предложения по совершенствованию соответствующей нормативной базы публичных слушаний. Такой подход представляется перспективным, так как «... часто мы не видим или игнорируем связь между прошлым и современным, предпочитая не знать, что законы генофонда сплошь и рядом бывают сильнее юридических законов» [7, с. 93].

\section{Правовой институт публичных слушаний: базовые идеи и проблемы их практической реализации}

В соответствии ст. 28 Федерального закона «Об общих принципах организации местного самоуправления в Российской Федерации» от 06.10.2003 N 131-Ф3 закреплено, что публичные слушания проводятся для обсуждения проектов муниципальных правовых актов по вопросам местного значения с участием жителей муниципального образования. В соответствии с данной нормой федерального законодателя в актах муниципалитетов о проведении публичных слушаний закрепляется норма о том, что в публичных слушаниях могут принять участие любой житель муниципального образования, достигший возраста 18 лет и обладающий избирательным правом. В научной литературе даже обсуждается предложение о наделении правом участия в публичных слушаниях иностранных граждан, проживающих на территории муниципального образования, а также собственников недвижимого имущества, расположенного в границах муниципалитета [8, с. 4].

Таким образом, в действующем законодательстве Российской Федерации последовательно проводится идея всеобщности участия населения и равных процедурных прав всех категорий населения при участии в публичных слушаниях. Однако, при всей ее демократичности, практическая реализация данной идей в процессе проведения публичных слушаний приводит к ряду проблем.

1) Анализ практики проведения публичных слушаний в разных муниципалитетах Российской Федерации ставит перед теоретиками муници- 
пального права вопрос о том, для достижения какой основной цели проводятся публичные слушания. Является ли основной целью проведения публичных слушаний проведение своеобразного митинга жителей и получение множества разнородных, противоречивых, спонтанных мнений или же публичные слушания должны быть ориентированы на получение здравых, предварительно продуманных рекомендаций от жителей муниципального образования, представляющих крупные территориальные, социальные или профессиональные группы местного населения и пользующихся их поддержкой и уважением?

2) Рассмотрение субъектного состава участников публичных слушаний с неизбежностью приводит исследователей данного общественного института к рассмотрению проблемы, связанной с определением основных критериев определения оптимального состава участников публичных слушаний. Является ли приоритетным обеспечение равенства процедурных форм участия в публичных слушаниях для всех жителей муниципального образования или необходимо вводить градацию прав участников публичных слушаний в зависимости от того, какое количество жителей они представляют и их квалификации в обсуждаемом вопросе (по аналогии с выделением категории экспертов)?

Ответ на данный вопрос является актуальным при проведении резонансных публичных слушаний, предполагающих участие большого количества жителей и ограниченность организаторов публичных слушаний в предоставлении всем желающим возможности для публичного изложения своей позиции.

3) В результате анализа практики проведения публичных слушаний можно сделать вывод о том, что в процессе обсуждения резонансных вопросов, вынесенных на публичные слушания, нередко чрезвычайно активно участвуют следующие категории местных жителей:

a) не обладающие даже минимальными знаниями в обсуждаемом вопросе,

б) использующие возможность выступления на публичных слушаниях для выплеска эмоций, критики власти, самопиара и рекламы своих идей, совершенно не связанных с темой публичных слушаний,

в) страдающие психическими отклонениями в различных формах.

Очевидно, что отсутствие правовых механизмов отсечения подобных участников публичных слушаний от осуществления публичных выступлений не только затрудняет их проведение, создает проблемы для конструктивного обсуждения вопросов, но и препятствует выявлению мнения большинства здравомыслящего населения.
Вероятно, ответить четко на поставленные вопросы достаточно сложно, если оперировать такими достаточно абстрактными категориями, как уровень муниципальной демократии, развитие самоуправленческих начал, вовлеченность населения в процесс осуществления местного самоуправления, развитие самоуправленческой инициативы. В связи с этим, по мнению автора, для достижения объективного знания по данным проблемам, перспективнее обратиться к истории вопроса и проанализировать, как решались данные вопросы в предшествующих исторических формах Российской диалоговой демократии.

Если же обратиться к практике функционирования вечевых и народных (копных) собраний, то следуетуказать, что они проводилисьна иныхпринципах формирования их участников. Как указывает в своей работе Н. Иванишев [5], исследуя работу народных собраний в сельских общинах Юго-Западной России в 16-17 веках, ссылаясь на архивные источники, «...не всЂ лица, принадлежавшія къ сельской общинЂ, составляли народное собраніе и участвовали въ его совЂщаніяхъ; это право предоставлялось однимъ только домохозяевамъ, имЂвшимъ постоянную осЂдлость. Ихъ сыновья и братья, не имЂвшіе отдЂльныхъ хозяйствъ, ... являлись въ собраніе только по особому требованію копы и при томъ не для совЂщанія, а только для свидЂтельскихъ показаній» [9].

В соответствии с информацией, содержащейся в исследовании, проведенном И.Д. Беляевым, новгородское Вече не было местом сбора беспорядочной толпы, а имело наперед известное соединение граждан, которые являлись на вече со своими старостами, своими общинами, уличане своей улицей. Самостийное сборище граждан (толпа бездумных бродяг и голытьбы) не могло принимать каких-либо решений. Решения, с которыми считались князья, могло принимать только Вече, собранное с соблюдением законных форм (правильное Вече) [4].

Приведенные примеры функционирования указанных форм древней диалоговой демократии свидетельствуют о том, что в основе их работы лежала не идея всеобщности участия населения в публичных слушаниях, а идея, предполагающая представительный характер участников публичных слушаний (формирование основы участников публичных слушаний из представителей населения, пользующихся уважением и доверием жителей). Вероятно, данную идею, в определенной мере уменьшающую вероятность принятия ошибочных решений при помощи несведущего большинства, есть смысл использовать и в настоящее время при определении состава участников такой современной формы диалоговой демократии, как публичные слушания. 


\section{Административное и муниципальное право 10 (106) • 2016}

\section{Проведение публичных слушаний в России: основные технологические проблемы}

Существующая к настоящему времени нормативная база и практика проведения публичных слушаний в Российской Федерации позволяет выделить ряд крупных блоков актуальных практических проблем, связанных с технологией реализации данной современной формы диалоговой демократии.

1. Блок проблем, связанных с совершенствованием общей процедуры и расширением вариативности форм проведения публичных слушаний.

В настоящее время процедура проведения публичных слушаний детально закрепляется в нормативных актах муниципальных образований и, несмотря на их многочисленность, она является стандартной. Публичные слушания, как правило, проводятся в форме собраний жителей муниципального образования, достигших возраста 18 лет и обладающих избирательным правом.

Однако, на сегодня назрела потребность в расширении вариативности форм проведения публичных слушаний. Решением данной проблемы может явиться законодательное закрепление на федеральном уровне следующих возможных форм проведения публичных слушаний:

1) Публичные слушания по проектам муниципальных нормативных правовых актов, оперативно (в сокращенные сроки) проводимые в рамках сессии представительного органа.

2) Публичные слушания по проектам муниципальных ненормативных правовых актов, оперативно (в сокращенные сроки) проводимые оперативно проводимые исполнительными органами местного самоуправления.

3) Публичные слушания по проектам муниципальных нормативных и ненормативных правовых актов, проводимые в форме массового обсуждения с использованием современных коммуникационных технологий, имеющихся в сети Интернет (диалоговые площадки интернет-сайтов, интернет форумы...).

4) Публичные слушания по проектам муниципальных нормативных и ненормативных правовых актов, проводимые в форме нескольких последовательных собраний жителей с одновременным использованием современных коммуникационных технологий, имеющихся в сети Интернет.

2. Блок проблем, касающихся процедурных вопросов назначения публичных слушаний.

Как указывает в своей работе В.Н. Бровченко, 0.Ю. Дегтярев, Г.С. Кириенко проблемным на сегодня является вопрос о том, является ли назначение публичных слушаний по инициативе населения правом или обязанностью соответствующего органа му- ниципального образования. Вправе ли соответствующий орган отказать инициативной группе граждан в проведении публичных слушаний по мотиву нецелесообразности? Для снятия поставленных вопросов в положении о публичных слушаниях они предлагают четко закрепить основания для отказа [8, с. 3].

Помимо этого, практика проведения публичных слушаний в различных российских муниципалитетах обозначила проблему, связанную с проведением повторных публичных слушаний по одному вопросу. На сегодня существует потребность в ведении нормативных ограничений для предпринимательских структур, желающих взять местное население «измором» и добивающихся проведения многократных публичных слушаний по одному и тому же вопросу до получения требуемого им результата.

3. Блок проблем, связанных с процедурными вопросами формирования и определения состава комиссии по проведению публичных слушаний.

Проблемы данного блока обусловлены тем обстоятельством, что, как правило, состав комиссии по проведению публичных слушаний формируется полностью из муниципальных служащих. В связи с этим, при проведении публичных слушаний часто определяющей является позиция муниципалитета.

4. Блок проблем, связанных с формированием перечня лиц, приглашаемых для участия в публичных слушаниях.

Проблемность данного аспекта публичных слушаний проистекает из предыдущего блока проблем и связана с тем, что при формировании числа экспертов и других приглашенных для выступления лиц нужно исходить из принципа, предполагающего предоставление права на публичное выступление представителям разнообразных точек зрений. Однако, при реализации указанного принципа следует учитывать какое количество жителей и насколько широкую группу местного населения представляет тот или иной кандидат для персонального приглашения для выступления на публичных слушаниях.

5. Блок проблем, обусловленных выбором времени и места проведения публичных слушаний.

Данный блок проблем связан с широко распространенной в муниципалитетах практикой проведения публичных слушаний в рабочие дни в неудобное для работающего населения время, что ограничивает возможность личного участия в слушаниях всех заинтересованных лиц. Помимо этого вопросы вызывает практика проведения публичных слушаний по вопросам землепользования и застройки в муниципальных зданиях, территориально удаленных и не являющихся ближайшими к объектам обсуждения. 
6. Блок проблем, связанных с перечнем вопросов, выносимых на публичные слушания и информированием населения о предстоящих публичных слушаниях.

Проблемы данного блока проистекают из муниципальной практики проведения публичных слушаний одновременно по нескольким вопросам или объектам, расположенным в разных частях муниципального образования одним и тем же составом участников публичных слушаний. Помимо этого совершенствования требуют способы оповещения населения муниципального образования о предстоящих публичных слушаниях.

7. Блок проблем обусловленных низкой явкой населения для участия в публичных слушаниях.

Данный блок проблем проистекает из того обстоятельства, что основной целью публичных слушаний является выяснение преобладающего мнения населения по тому или иному вопросу. Если же жители не приходят на публичные слушания, то за их мнение может быть выдано мнение узкой группы жителей, по разным причинам принявших участие в публичных слушаниях, или мнение сотрудников администрации, которые очень часто (для того, чтобы публичные слушание состоялись) вынуждены в принимать участие в публичных слушаниях.

8. Блок проблем, связанных с процедурными вопросами проведения публичных слушаний.

Проблемы, связанные с процедурными вопросами проведения публичных слушаний, проистекают из того, что достаточно проблематично установить единую последовательность выступлений, единый лимит времени для выступлений и общую продолжительность публичных слушаний, проводящихся по различным вопросам. На практике проблемы вызывает определение последовательности выступающих, соблюдение формы представления письменных материалов, применение дисциплинарных мер к нарушителям регламента.

9. Блок проблем, касающихся подведения итогов состоявшихся публичных слушаний.

Проблематичность указанному блоку проблем придает то обстоятельство, что в практике проведения публичных слушаний часто используется голосование по вопросам, вынесенным на публичные слушания. Оно проводится в целях определения результатов публичных слушаний в форме рекомендаций, представляющих собой мнение большинства участников публичных слушаний. Очевидна большая спорность подобного способа подведения итогов состоявшихся публичных слушаний, предполагающего игнорирование мнений части участников публичных слушаний и не способствующего достижению согласия и единства, как среди участ- ников публичных слушаний, так и среди жителей муниципального образования.

11. Блок проблем, связанных с учетом результатов состоявшихся публичных слушаний.

Указанные проблемы вызваны тем, что в муниципальной практике существует неоднозначность в учете результатов состоявшихся публичных слушаний. С одной стороны, несмотря на рекомендательный характер публичных слушаний, их результаты очень часто используются руководителями муниципалитетов для оправдания того или иного непопулярного решения, с другой стороны, результаты публичных слушаний нередко игнорируются муниципальными органами и должностными лицами [10].

Направления совершенствования института публичных слушаний, как основной формы современного диалогового народовластия в России.

Формулируя направления совершенствования современного российского правового института публичных слушаний представляется полезным тезисно сформулировать следующие практические предложения, направленные на совершенствование его содержания.

1. Необходимо расширять вариативность форм проведения публичных слушаний.

2. Есть смысл в положениях о публичных слушаниях четко закреплять основания для отказа инициативной группе граждан в проведении публичных слушаний.

3. Назрела необходимость в нормативной регламентации оснований для проведения повторных публичных слушаний по одному и тому же вопросу.

4. Представляется обоснованным нормативно ограничить объем представительства муниципальных и государственных служащих в составе комиссии по проведению публичных слушаний.

5. Есть смысл в положениях о публичных слушаниях развести понятия право на участие в публичных слушаниях и право на выступление в публичных слушаниях, закрепив преимущественное право на осуществление последнего за жителями муниципального образования, представляющими крупные территориальные, социальные или профессиональные группы местного населения и пользующихся их поддержкой и уважением.

6. Исходя из практики проведения публичных слушаний разумно будет нормативно закрепить на федеральном уровне правила определения времени и места проведения публичных слушаний.

7. Имеется необходимость законодательного запрета на проведение публичных слушаний одновременно по нескольким вопросам или объектам, расположенным в разных частях муниципального образования одним и тем же составом участников публичных слушаний. 
8. Есть смыл нормативно закрепить на федеральном уровне запрет на проведение голосования по вопросам, вынесенным на публичные слушания, в целях определения результатов публичных слушаний в форме рекомендаций, отражающих мнение большинства участников публичных слушаний.

9. Назрела необходимость нормативной формализации и конкретизации оснований учета или неучета результатов публичных слушаний органами и должностными лицами местного самоуправления.

Приведя предложения по совершенствованию существующей схемы проведения публичных слушаний в Российской Федерации, в заключение хотелось бы указать на то обстоятельство, что все вышеуказанные предложения носят частный характер и не решают основной проблемной стороны современной технологии проведения публичных слушаний, связанной с их субъектным составом. Публичные слушания в современном виде, к сожалению, во многом напоминают организованный митинг жителей, оповещенных о его проведении. Как правило, трудно спрогнозировать сколько жителей придут для участия, насколько представительным будет состав участников, насколько мнение участников публичных слушаний будет отражать преобладающее мнение населения территории.

Вместе с тем, основные перспективы совершенствования технологии проведения публичных слушаний видятся в направлении совершенствования его нормативной базы, предполагающей закрепление таких форм их проведения, которые обеспечат (по аналогии с проведением вечевых собраний) организованное и регулярное участие в публичных слушаниях легитимных представителей микрорайонов, улиц, домов, органов территориального общественного самоуправления и других значимых сообществ местных жителей. Очевидно, что подобная процедура проведения публичных слушаний во многом снимет их митинговый характер, снизит вероятность искажения действительного мнения населения и будет способствовать налаживанию постоянного и продуктивного диалога жителей и власти, который жизненно необходим российской публичной власти в настоящих непростых социально-экономических условиях.

\section{Библиография:}

1. Зайцев А.В. Делиберативная демократия как институциональный диалог власти и гражданского общества // NB: Проблемы политики и общества. - 2013. - № 5. - C.29-44. DOI: 10.7256/2306-0158.2013.5.689. URL: http://enotabene.ru/pr/article_689.html (дата обращения: 16.08.2016).

2. Johnson D. W., Johnson R. T. (University of Minnesota) Civil Political Discourse in a Democracy: The Contribution of Psychology// Peace and Conflict: Journal of Peace Psychology. - Volume 6. - № 4, - 2000. - P. 84-95.

3. Зенин С.С. Публичные слушания и народное вече (исторический аспект // История государства и права. -2008. - № 15. - С. 38-44.

4. Беляевъ И.Д. Судьбы земщины и выборного начала на Руси. М., - 1905. - 136 с.

5. Иванишевъ Н. О древнихъ сельскихъ общинахъ въ Югозападной Россіи / Изданіе Кіевской Археографической Коммиссіи.-К.: В тип. Федорова и Мин., - 1863. - 267 с.

6. Ключевский В.О. Сочинения: В 9 т. Курс русской истории. Т. 1. М., - 1997. - 345 с.

7. Федотов Г.П. Рождение свободы // Собрание сочинений: В 12 т. Т. 9. М., - 2004. - 311 с.

8. Бровченко В.Н., Дегтярев О.Ю., Кириенко Г.С. О некоторых вопросах порядка организации и проведения публичных слушаний в России // Гражданское общество в России и за рубежом. - 2013. - N 3. - С. 54-63.

9. Книга гродская Луцкая 1583-го года, листъ 255-259.

10. Соловьев С.Г. Состав муниципального правонарушения: проблемы теории и практики // Государство и право.2015.-№3.-С. 51-60.

11. Коломеец Н.Е. Конституционно-правовые основы реализациинаселением прав граждан в сфере территориальногоустройства субъекта Российской Федерации // Право и политика. - 2013. - 8. - C. 994-1002. DOI: 10.7256/18119018.2013.8.9292.

12. Липинский Д.A. Social Bases of Positive Responsibility // SENTENTIA. European Journal of Humanities and Social Sciences.-2015.-3.-C. 41-69. DOI: 10.7256/1339-3057.2015.3.16009. URL: http://www.e-notabene.ru/psen/ article_16009.html

\section{References (transliterated):}

1. Zaitsev A.V. Deliberativnaya demokratiya kak institutsional'nyi dialog vlasti i grazhdanskogo obshchestva // NB: Problemy politiki i obshchestva. - 2013. - № 5. - S.29-44. DOI: 10.7256/2306-0158.2013.5.689. URL: http://e-notabene.ru/pr/ article_689.html (data obrashcheniya: 16.08.2016).

2. Johnson D. W., Johnson R. T. (University of Minnesota) Civil Political Discourse in a Democracy: The Contribution of Psychology// Peace and Conflict: Journal of Peace Psychology. - Volume 6. - № 4, - 2000. - P. 84-95.

3. Zenin S.S. Publichnye slushaniya i narodnoe veche (istoricheskii aspekt // Istoriya gosudarstva i prava. - 2008. - № 15. S. 38-44. 
4. Belyaev" I.D. Sud'by zemshchiny i vybornogo nachala na Rusi. M., - 1905. - 136 s.

5. Ivanishev" N. O drevnikh" sel'skikh" obshchinakh" v" Yugozapadnoi Rossii / Izdanie Kievskoi Arkheograficheskoi Kommissii.-K.: V tip. Fedorova i Min., - 1863. - 267 s.

6. $\quad$ Klyuchevskii V.O. Sochineniya: V 9 t. Kurs russkoi istorii. T. 1. M., - 1997. - 345 s.

7. Fedotov G.P. Rozhdenie svobody // Sobranie sochinenii: V 12 t. T. 9. M., - 2004. - $311 \mathrm{~s}$.

8. Brovchenko V.N., Degtyarev O.Yu., Kirienko G.S. O nekotorykh voprosakh poryadka organizatsii i provedeniya publichnykh slushanii v Rossii // Grazhdanskoe obshchestvo v Rossii i za rubezhom. - 2013. - N 3. - S. 54-63.

9. Kniga grodskaya Lutskaya 1583-go goda, list" 255-259.

10. Solov'ev S.G. Sostav munitsipal'nogo pravonarusheniya: problemy teorii i praktiki // Gosudarstvo i pravo.-2015.-№3.S. 51-60.

11. Kolomeets N.E. Konstitutsionno-pravovye osnovy realizatsiinaseleniem prav grazhdan v sfere territorial'nogoustroistva sub"ekta Rossiiskoi Federatsii // Pravo i politika. - 2013. - 8. - C. 994-1002. DOI: 10.7256/1811-9018.2013.8.9292.

12. Lipinskii D.A. Social Bases of Positive Responsibility // SENTENTIA. European Journal of Humanities and Social Sciences.2015.-3.-C. 41-69. DOI: 10.7256/1339-3057.2015.3.16009. URL: http://www.e-notabene.ru/psen/article_16009.html 